\title{
Genuine Knowledge and Conclusion Based on the Practice of Urban and Rural Ecological Corridor——The Design of Ecological and Green Corridors in Shanhaiguan District
}

\author{
Zheng Shi, Ning Wang, Lei Li \\ Urban and Rural Planning, \\ Agricultural University of Hebei Province, \\ Baoding, 071000, China
}

\begin{abstract}
The ecological corridor is derived from the foreign advanced concepts of developed countries, which protects the urban and rural mechanism and context, intensively utilizes land resources and conforms to the requirements of the construction of ecological urban and rural development. The design of Shanhaiguan District Cherry Vale greenway is based on the resources of local mountain, water, springs, and sea, using the greenway design means to design travel, relaxation, culture and other node elements, in which gathers many scattered resources along the corridor and preponderant landscape as dominant resources, not only protect the ecosystem of the natural environment, but also promote the urban and rural harmonious development of social economy.
\end{abstract}

Keywords-local resources; ecological corridor; the way of ecological design; urban and rural industry ecosystem

\section{BACKGROUND OF THE RESEARCH ON THE URBAN AND RURAL ECOLOGICAL CORRIDORS}

Corridor is a concept in landscape ecology, it is different from linear or zonal landscape elements on both sides of the matrix, including roads, rivers, green belts, tree-lined belt are corridors in the urban and rural areas [1]. The definition of ecological corridor meaning protecting the species diversity, filtering pollutants, preventing soil erosion, windbreak and sand-fixation, controlling flood, etc, which provides the function of ecological service. Ecological corridor is mainly composed of vegetation, water, landscape elements, and it's the same as "green corridor" in concept. Rural and urban ecological corridor is the integration of green space resources, which uses green ecological health corridor to the organic connection. Improving the rural and urban green land ecological benefit [2], economic benefit and social benefit, is one of the important choice of promoting scientific development.

In today's rapid development of urban and rural integration, urban and rural problems are highlighted, for example: we have a fast progress of urbanization, and at the same time, urban rapid development do not give priority to respect the local ecological environment, which caused destruction of ecology of urban and rural habitats[3]. In this paper, the ecological corridors are the maintenance of urban and rural ecological bridge, to protect the mechanism of urban and rural areas and are also protect arable land, intensively utilize the land resources.

\section{SIGNIFICANCE OF THE ECOLOGICAL CORRIDOR}

Ecological corridor has many important functions: controlling the local regional environment, preventing pollution and soil erosion and renovating the function of ecosystem diversity [4]. Building a complete urban and rural road system, promoting the logistics links, prompting the country to support the city and urban to promote the countryside, and the economy, industry and culture to support each other. To make the urban and rural area become regional, scaled, systematic network industry pattern. It's important for mining local natural resources, improving the industry chain, enhancing the quality of tourism, business services, and it' $\mathrm{s}$ the key link to form the urban and rural ecological circulation industry's chain.

III. EXPLORATION AND ANALYSIS OF THE ECOLOGICAL CORRIDOR CONSTRUCTION IN SHANHAIGUAN DISTRICT

A. The present ecological and environmental situations in Shanhaiguan District under the urban-rural integration

Shanhaiguan District is a typical urban-rural separation, dualization pattern evident in the region, it is not difficult to see relatively fast urban development, rural backward, not only restrict the urban and rural development as a whole[5], as well as rural and urban and rural integration of ecological environment and culture inheritance are facing serious challenges.

\section{B. The ecological greenway planning of Cherry Vale in Shanhaiguan District}

\section{1)Description of Cherry Vale greenway}

Greenway is located in northwest of Qinhuangdao Shanhaiguan District, $7.9 \mathrm{~km}$ from downtown. The green lane west from Wangyu Road, East Yansai Lake Road ends, the total length of $3787 \mathrm{~m}$ (the figure as can be seen from table I), is a bond links the northern and southern mountainous rural town. Be closing the Shanhaiguan District and the northern of mountainous area, fully mobilize the available natural and historical resources, subtle solves the environment, the humanities, the industry and other issues. 
TABLE I THE GREENWAY TYPE LIST

\begin{tabular}{|c|c|c|c|}
\hline genre & instructions & length（m) & $\begin{array}{l}\text { breadth } \\
(\mathrm{m})\end{array}$ \\
\hline $\begin{array}{l}\text { battery } \\
\text { lane }\end{array}$ & $\begin{array}{l}\text { Began by Wangyu Road intersection, along } \\
\text { Cherry Valley Road, the road to reach the }\end{array}$ & 3787 & 3 \\
\hline bikeway & Yansai Lake & 3787 & 1.5 \\
\hline footpath & $\begin{array}{l}\text { Cherry Valley Road to the backbone, } \\
\text { surrounded by dirt road to slip greenway } \\
\text { network system }\end{array}$ & 7223 & 1.2 \\
\hline
\end{tabular}

2)Theme of Cherry Vale greenway

The theme of greenway: humanity - Wangyu village houses; Industry - Cherry Vale; Environment - WuQuan Mountains, fields; Culture - relic; Science methane-generating pits, biofertilizer. Reflect the geographical landscape of the cherry, dwellings, field,"mountain, forest, farm, garden" perfect combined, have both of the characteristics of the times and rural culture of modern ecological tourism and leisure corridor(as can be seen from picture1).

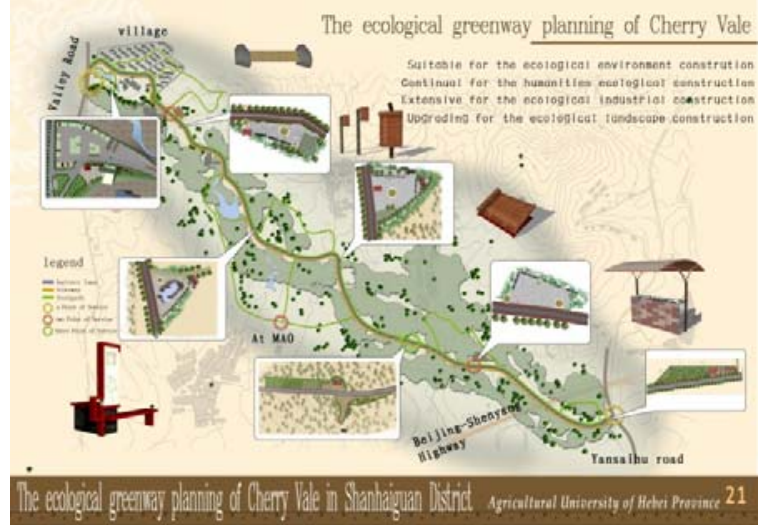

Picture 1

\section{3)Overall arrangement of Cherry Vale greenway}

The greenway is divided into four parts: "the greenway of peasant cultural leisure"; "The greenway of cherry orchard landscape "; "The greenway of historic cultural experience "; "the green way of rural outskirts landscape ".

\section{SOME FINDINGS OF CHERRY VALE GREENWAY CONSTRUCTION}

\section{A. Suitable for the ecological environment construction}

Attach great importance to the role of the natural ecology: the greenway is basement with the natural scenery and artificial landscape,not change the land properties, protect the ecological environment and natural resources, providing corridor for animal and plant breeding, migration and habitat, and shaping a sustainable urban and rural ecological environment and the natural landscape.

Use of natural resources: WuQuan Mountain have rich vegetation(about 1000 acres); About $5000 \mathrm{mu}$ of local cherry orchard, as an important part of integrating leisure, tourism, sightseeing, picking. Provides a good natural environment of the basement for the greenway planning.
Without changing land nature, protects the farmland, forest land and other natural resources, favorable habitat conditions for plants and animals[6]. Greenway will connect each node within the scope of the green corridor, as well as connect ecological nodes and plaques, which has played an important role in its overall planning for the ecological environment.

\section{B. Continual for the humanities ecological construction}

Be respect facing the humanities: the greenway is the link of the series village,landscape node and city, make a connection within the local cultures in most low-carbon, shows the form of low carbon to local residents in the most simple, and plain lifestyle, in the notice of intensive land use at the same time, with minimal intervention to achieve the optimal effect.In transient dynamic experience engaging in manner, with the least interference and influence of local residents way of life, the tourists participate in "dynamic" and "static" combined with the local way of life, blend the humanities culture, promote the outside world, urban area, communication between the integration of urban and rural areas and villages, constitute the humanities ecosystem.

i) "the greenway of peasant cultural leisure"section: the greenway channel using the village road to design, focal represented by WuQuan Mountain scenery and represented by valley village folk culture at Shanhaiguan District. This section focuses on the humanities folk greenway communion with the natural landscape, urban and rural residents and visitors can enjoy the countryside and create beautiful mountain scenery, but also to experience space travel tours rural folk culture. The future will also consider introducing organic way of tourism forms, and strive to develop courtyard economy, balcony and other economic model.

ii) "The greenway of historic cultural experience" section: In the local historical culture as the foundation, use the ancient akimichi, ruins protection as the center to explore as the background, the cherry orchard and bacterial manure plant knowledge propaganda as supplement, appropriate development and historical experience and leisure tourism(as can be seen from picture2).

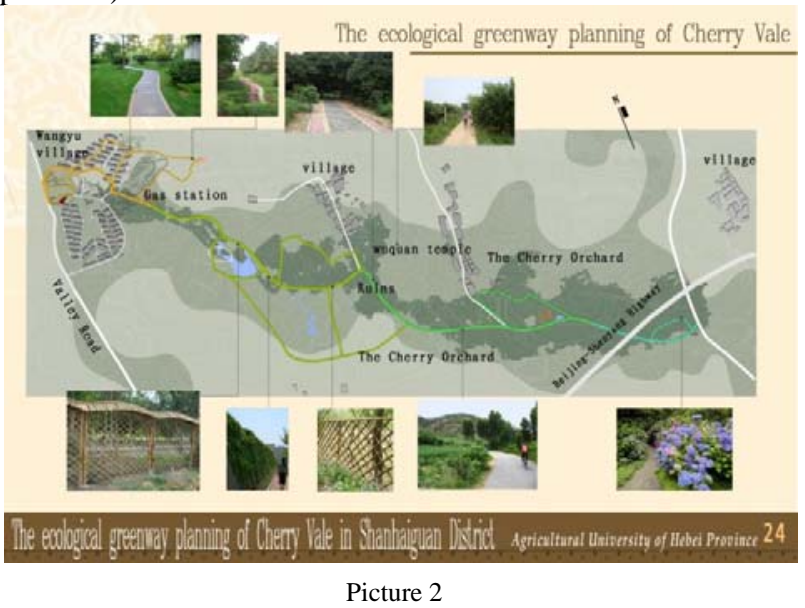




\section{Extensive for the ecological industrial construction}

Promote industrial economic cycle: Green way focus on agricultural development, the greenway for a line from Shanhaiguan in the village, the natural landscape, cherry orchard, and complete the cherry industry chain, developing by planting, sightseeing picking to product processing, operating sales of ecological industry chain. Aims to promote the environmental construction as the foundation, at the same time, the development of economy realistic industry as opportunity and promote local economic, form the "raw materials - during link postpartum link - cold chain circulation - consuming guidance" as the industry chain. Greenway of cohesion between urban and rural areas has prompted logistics, circulation, and have connection with sales of products, the introduction of science and technology, talented person's absorption.

i) "The greenway of cherry orchard landscape" section: cherry vale road as the main, to the sides of the cherry orchard for the skeleton, with local famous sightseeing leisure agriculture and agricultural production as one of the industry. The development direction of The Cherry Orchard at the core, Cherry Orchard brand-based, vigorously develop tourism picking cherries, and in the future focus on the deep processing of cherries and other products, and strive to build a sound industrial chain cherries and other crops.

ii) Jufeng ecological garden covers an area of 177 acres, is one of a number of green agricultural eco-tourism garden. Rural village Wuquan Mountain original ecological leisure garden, covering 400 acres. All district buildings were built with natural materials, natural simplicity. Ecological garden, holiday garden is a strong local support, including product marketing, branding, and extends the range of tourism services.

\section{Upgrading for the ecological landscape construction}

Improve natural landscape affinity: Greenway link rural and urban landscape, the transition to the continuity of the landscape urban and rural areas, considering the dynamic visual experience, take advantage of the special nature of the different viewing speed, to take "action concept" design approach, relying on the natural scenery, extending the visual corridor. Planning pedestrian greenway $7223 \mathrm{~m}$, battery-lane $3787 \mathrm{~m}$, bike lanes $3787 \mathrm{~m}$, so that the landscape is considerable, make people can watch, reach, play.

i) "the greenway of rural outskirts landscape": Configuration corresponds tourism landscape resources. Formation of Landscape Layout "Hanakagami Garden" as the center ,along the axis of cherry valley road ,around the mountain country to ring in the spatial pattern. And focus on the establishment of "travel, recreation" ,as one of the natural landscape, the premise of full respect for nature, focusing on people-oriented(as can be seen from picture3).

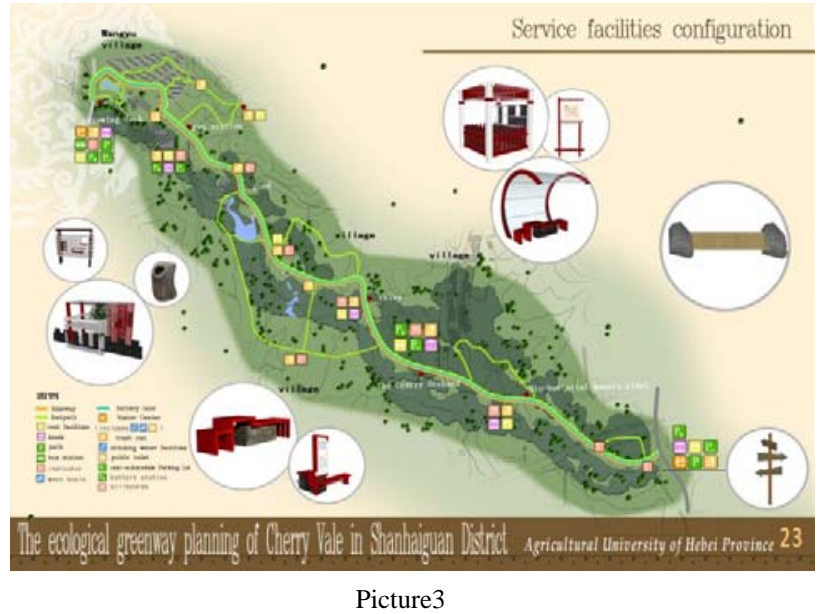

ii) The rural dwellings landscape nodes: New residential building is not only the landscape, but also the integration of landscape and residential landscape. The Wangyu Village is a new residential construction in Hebei province pilot, which have the characteristics of mountain building, the village construction mountain potential,with the "economy" requirements of green building. This landscape node combine with residential construction, cherry picking, climbing Wuquan Mountain and other content set greenway service center, observation deck, parking and other facilities.

\section{E. Guiding for the ecological environmental construction by science and technology}

Combination of technology and ecology: Connection with the development of technology and ecology, developing ecological way of environmental protection combining with science and technology, applying to the local conditions. The change of high and new technology promotion methods, also make the local environmental protection, improve the way to meet the new technology, low energy consumption, high efficiency. Used to introduce new technologies, fusion in agricultural production, to form the agricultural demonstration demonstration is also better for the advantage of science and technology advancing rural industry.

i) Energy saving low carbon landscape nodes: The Wangyu Village of biogas station both energy saving and conducive to the protection of the ecological environment. Gas station in the ground with a volume of 4000 cubic meters of gas pool, to produce biogas generated from each, can not only includes the farmhouse in the village for more than 800 villagers, hotel restaurant supply biogas, also can ensure that after several years, village scale needs. It is also can used for agricultural production, such as greenhouse heat preservation, baking products, reserve food and fruit fresh keeping, etc.

ii) the node to promote rural science and technology: a bio-bacterial manure plant is located on the cherry vale road, to provide protection for green technology organic cherry cultivation and production. The main raw material 
for the local livestock waste and shale, plant stalks, microbial agents and other local materials turning waste into treasure, to reduce costs and land pollution and ensure the sustainable development of aquaculture. Conform to the circular economy "livestock and poultry breeding, biological organic fertilizer, planting green" circulation patterns.

\section{CONCLUSION}

Urban and rural ecological corridor promote zones of contact and also solve the problem of a series of urban and rural construction, restoration of urban and rural ecological environment, improve the appearance of urban and rural landscape, continuation of historical context, make rural and urban tourism industry interaction, formed complementary advantages chain of industrial ecosystem circulation, avoiding urban sprawl, strategic control important ecological resources of urban and rural areas.

Greenway of design is based on the unique resources of mountain, water, springs, sea, using the greenway to travel, leisure, culture and other node element to design, by using the urban and rural greenway to spread out along the many various resources, landscape advantage aggregated into advantage resources, set ecological environment protection, low carbon travel, culture, entertainment, and other functions into one, which protect natural environment, and enhance the harmonious development of urban and rural social and economic.

\section{REFERENCES}

[1] Yu K, Li D, Li N. The evolution of greenways in China[J].Landscape and Urban Planning, 2006, 76(1-4): 223-238.

[2] Naveh Z,Lieberman A S . Landscape Ecology:Theory and Application[M]. New York: Springe-Verlag,1984.

[3] Yanitsky, The city and ecology[M] . Moskow ,Nanka ,1987.

[4] Turner T. Greenway planning in Britain: recent work and future plans [J]. Landscape and Urban Planning,2006,76(1): 240- 251.

[5] Roseland M. Dimensions of the future :An Ecocity overview[M] ,1997.

[6] Pyke,C.R.The implications of global priorities for biodiversity and ecosystem services associated with protected areas[J].Ecology and Society,2007,12(1): 4. 